\section{Intravitreal steroids may facilitate treatment of Eales' disease (idiopathic retinal vasculitis): an interventional case series}

M Ishaq ${ }^{1}$, AH Feroze ${ }^{2}$, M Shahid ${ }^{2}$, MA Baig², SS Ameen², SH Feroze ${ }^{4}$ and RA Chishti

\begin{abstract}
Purpose Eales' disease is an idiopathic peripheral perivasculitis leading to proliferative vascular retinopathy, recurrent vitreous haemorrhages, and tractional retinal detachment. It is an elusive cause of blindness in young, otherwise healthy individuals. We studied the effects of intravitreal triamcinolone acetonide (IVTA) in patients of Eales' disease, which may eventually reduce the side effects and cost of management, with results equivalent to or better than oral steroids.

Methods Ethics approval and prior patient consent were obtained. Fluorescein fundus angiograms (FFAs) of 12 eyes of 12 Eales' disease patients were taken before enrolment. These patients received $0.1 \mathrm{ml}$ of $40 \mathrm{mg} / \mathrm{ml}$ $(4 \mathrm{mg})$ intravitreal triamcinolone through pars plana under topical anaesthesia. Regular weekly follow-ups were initiated to ascertain Snellen visual acuity, intraocular pressure (IOP) with Goldman tonometer, and triple mirror examination. Fluorescein fundus angiography was again performed in the 8 th week to monitor response to treatment. Decrease in areas of late perivascular dye extravasation on fluorescein angiography was used as marker for improvement.

Results Ten out of a total of $\mathbf{1 2}(\mathbf{8 3 . 3 3 \% )}$ ) eyes treated with IVTA showed significant reduction of late leakage from retinal vessels on fluorescein fundus angiography. Two out of 12 eyes (16.67\%) did not show considerable decrease in late perivascular fluorescein dye leakage after 8 weeks of intravitreal triamcinolone injection. Two patients $(16.67 \%)$ had a significant rise in IOP after IVTA.
\end{abstract}

Conclusion Intravitreal steroids may be advocated for management of idiopathic retinal vasculitis without complications of systemic steroids, and minimize need for more invasive procedures.

Eye (2007) 21, 1403-1405; doi:10.1038/sj.eye.6702551; published online 15 September 2006

Keywords: retinal vasculitis; triamcinolone acetonide; proliferative vitreoretinopathy

\section{Introduction}

Eales' disease is an idiopathic obliterative vasculopathy primarily affecting the arterioles and venules of the peripheral retina of young adults. ${ }^{1-3}$ It is relatively more common in Indo-Pakistan Subcontinent and the Middle East, but cases have been reported throughout the world. ${ }^{4}$ The inflammatory vascular occlusion leads to a proliferative retinopathy, with serious sequelae such as recurrent vitreous haemorrhage and tractional retinal detachment. ${ }^{2,5}$ The patient remains unaware of early changes as central vision may not be severely affected.

It is usually a diagnosis of exclusion. Other systemic causes of retinal vasculitis must be investigated. Treatment options include systemic steroids, retinal photocoagulation to non-perfused retina, and early vitrectomy for recurrent vitreous haemorrhage. ${ }^{6-8}$ Oral steroids are usual management for Eales' disease, but prolonged systemic use of steroids is associated with serious ocular and systemic side effects.

Intravitreal steroids have been used in many posterior segment ocular pathologies. However, a couple of recent case reports exists about the
${ }^{1}$ Department of Ophthalmology, Army Medical College, Rawalpindi, Pakistan

${ }^{2}$ Department of Ophthalmology, Military Hospital, Rawalpindi, Pakistan

${ }^{3}$ Department of Ophthalmology, Pakistan Armed Forces, Military Hospital, Rawalpindi, Pakistan

${ }^{4}$ Islamic International Medical College, Rawalpindi, Pakistan

Correspondence:

AH Feroze,

Department of Ophthalmology, Military Hospital, House Number 40,

Askari 8

Airport Road

Rawalpindi,

Punjab 46000, Pakistan

Tel: + 92-333-5437029;

Fax: +92-51-5952232.

E-mail:

ahferoze@hotmail.com

Received: 12 February 2006 Accepted in revised form: 13 July 2006 Published online: 15 September 2006

Presented in part at the 9th Islamabad Congress of Ophthalmology, 9th till 11th April 2004 by Dr Muhammad Shahid 
response of Eales' disease with intravitreal steroids, as concluded after a Medline/Pubmed search using keywords 'Eales' and 'intravitreal triamcinolone'.9,10 The following case series gives an account of our experience with multiple patients of Eales' disease who received intravitreal triamcinolone acetonide (IVTA). Our aim is to successfully treat Eales' disease while avoiding side effects of prolonged systemic steroid therapy, limit the need for panretinal photocoagulation, and minimize the need for more invasive procedures.

\section{Materials and methods}

A prospective interventional case series was designed to study the response of Eales' disease patients to IVTA at the Military Hospital (MH), Rawalpindi, Pakistan, during 2004 through 2005. Ethics approval from the Institutional Ethical Committee was obtained and all efforts were made to remain true to the guidelines of the Declaration of Helsinki Principles. Patients were briefed on the purpose and procedures of the study and patient consent was taken before enrolment.

Suspected Eales' disease patients aged 20-35 years underwent exhaustive ocular and medical evaluation before labelling them as Eales' disease. Investigations included complete blood count with sickle cell screening, erythrocyte sedimentation count, blood sugar, blood coagulation profiles, antinuclear antibody test, serology for syphilis, and enzyme-linked immunosorbent assays for HIV, herpes simplex virus, and cytomegalovirus. Urine and stool analyses, Mantoux test, and chest X-ray were also performed. All test results were normal. Snellen visual acuity, Goldman applanation tonometer, triple mirror examination, and FFAs were performed on every patient before enrolment. FFA of all subject eyes showed staining of dilated vessels with late extravasation of the dye and corresponding areas of capillary nonperfusion.

Eales' disease patients with a recent vitreous haemorrhage in one eye were offered IVTA in the contralateral affected eye, in which the fundus was visible. The eyes with vitreous haemorrhage per se were not part of this study. Patients on oral steroids, or with any concomitant ocular disease, or where steroids were contraindicated; were excluded from this series.

Twelve eyes of 12 patients received IVTA. Patients were prepared in the operating theatre under aseptic environment and washed with $5 \%$ povidone iodine solution. Under topical anaesthesia, $0.1 \mathrm{ml}$ of aqueous humour was aspirated through limbus with $29 \mathrm{G}$ insulin needle. Then IVTA, $0.1 \mathrm{ml}$ of $40 \mathrm{mg} / \mathrm{ml}(4 \mathrm{mg})$ was injected through pars plana by another $29 \mathrm{G}$ insulin needle. The patients were asked to lie supine for half an hour after injection.
Regular weekly follow-ups measured the Snellen visual acuity, intraocular pressure (IOP) by Goldman tonometer, and triple mirror examination of the peripheral retina. A pressure elevation was defined as a sustained pressure of $24 \mathrm{~mm} \mathrm{Hg}$ or higher during followup. ${ }^{11}$ FFA was again performed in the 8 th week. Reduction in areas of late peripheral perivascular dye extravasation on FFA was used as the marker for improvement.

\section{Results}

All patients were men with mean age $30.18 \pm 4.16$ years. All patients had periphlebitis in at least one eye on initial presentation. Three $(25 \%)$ out of 12 patients also had a recent vitreous haemorrhage in the contralateral (nonstudy) eye. None of the patients studied had macular involvement. All eyes had best-corrected Snellen visual acuity of 20/20 (6/6) at the start of the study. None of the eyes showed change in Snellen visual acuity during the course of this follow-up.

Ten out of a total of $12(83.33 \%)$ eyes treated with IVTA showed significant reduction of leakage from retinal vessels on FFA. Eight out of nine (88.89\%) patients without vitreous haemorrhage in any eye showed improvement. In the three patients with vitreous haemorrhage in the contralateral eye, two patients $(66.67 \%)$ showed improvement in the eyes under study. Two out of 12 patients $(16.67 \%)$ did not show considerable decrease in late peripheral perivascular fluorescein dye leakage after 8 weeks of IVTA.

Two patients $(16.67 \%)$ had a significant rise in IOP after IVTA. One of them was well controlled on topical $0.5 \%$ Timolol, whereas the other underwent trabeculectomy. Most patients' IOP remained within pretreatment ranges.

Figures 1 and 2 show FFA of one patient treated with IVTA. Figure 1 shows tortuosity of the retinal vasculature with late extravasation of dye from the inflamed vessels. Figure 2 shows considerable reduction in the late peripheral perivascular leakage of fluorescein dye, 8 weeks after IVTA.

\section{Discussion}

Intravitreal steroids may decrease the need for chronic immunosuppressive therapy, improve patient compliance, and reduce the number of visits to the doctor. At our department, highly encouraging results of IVTA in Eales' disease support similarly promising reports from India. Both Pathengay et $a l^{9}$ and Agrawal et al $^{10}$ show good perivasculitis control in Eales' disease with IVTA, with minimal ocular or systemic side effects in their case reports., ${ }^{9,10}$ 


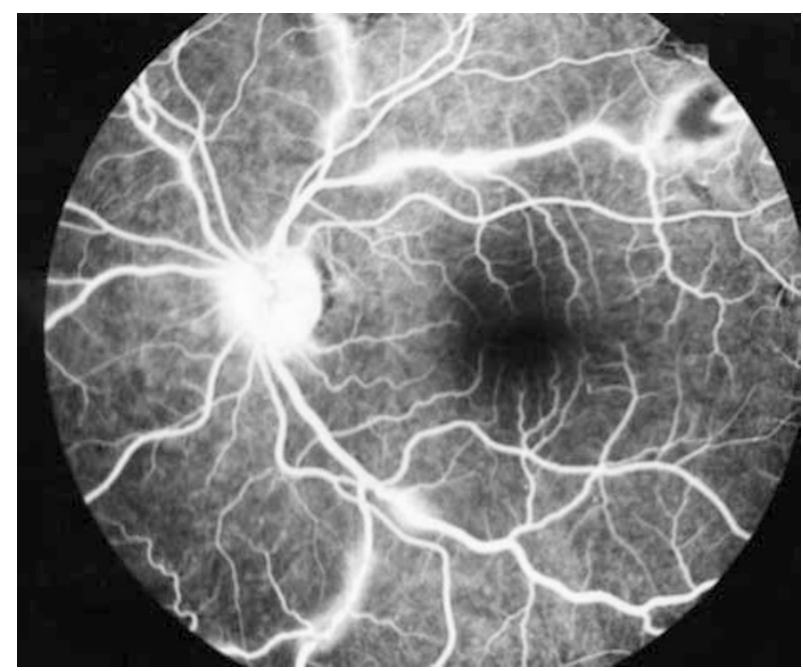

Figure 1 Left eye of a patient with Eales' disease. Note areas of capillary non-perfusion accompanying venous and late fluorescein dye leakage from areas of perivasculitis.

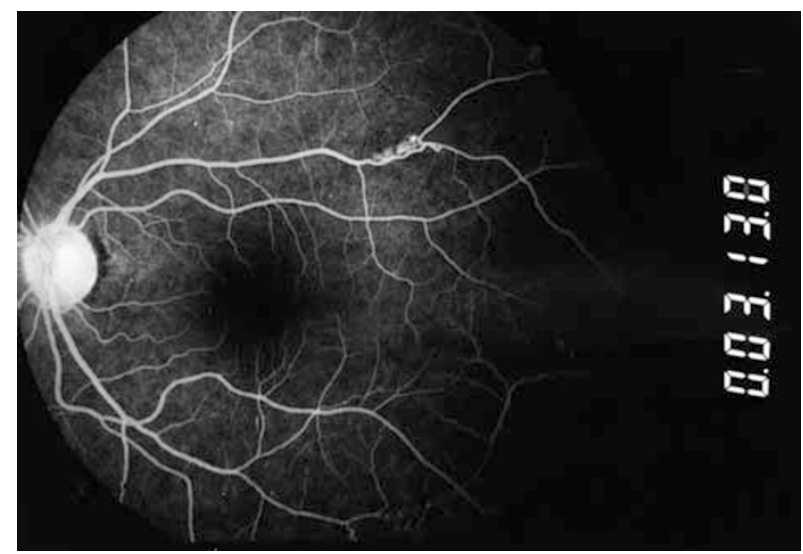

Figure 2 Same eye as in Figure 1, 8 weeks after intravitreal triamcinolone injection. Note the absence of venous beading and late perivascular fluorescein dye leakage.

Our results show that IVTA adequately controls perivascular inflammation with resultant decrease in late leakage of fluorescein dye from the retinal capillaries. More than $80 \%$ patients responded favourably to the treatment. Two patients had considerably raised IOP and were adequately controlled. Although macular pathology was not one of our exclusion criteria, our study group consisted of eyes with minimal macular involvement.

This study does not look at long-term follow-up of patients. Having enrolled our first patient in early 2004, we have regularly followed them up and they have shown no recurrence of symptoms in the subject eyes. None of the patients developed any significant ocular infection. This follow-up was not part of the study and hence no further comment can be made to this effect.

Our results reinforce the case reports by Pathengay et $a l^{9}$ and Agrawal et al. ${ }^{10}$ IVTA definitely controls posterior segment inflammation in Eales' disease. We propose a larger multicentre study to evaluate these findings and possibly a placebo-controlled multicentre trial can be undertaken in the future.

\section{Acknowledgements}

The project was funded by the authors at the Department of Ophthalmology, Military Hospital, Rawalpindi, Pakistan.

\section{References}

1 Elliot AJ. 30-year observation of patients with Eales disease. Am J Ophthalmol 1975; 80: 404-408.

2 Murphy RP, Gieser SC, Fine SL, Patz A. Retinal and vitreous findings in Eales disease. Invest Ophthalmol Vis Sci 1986; 27: 121.

3 Albert DM, Jakobiec FA. Eales' disease. In: Albert DM, Jakobiec FA (eds). Philadelphia: Principles and Practice of Ophthalmology: Clinical Practice. Saunders: Philadelphia, 1994, pp 1058-1062.

4 Das T, Biswas J, Kumar A, Nagpal PN, Namperumalsamy P, Patnaik B et al. Eales' disease. Indian J Ophthalmol 1994; 42: 3-18.

5 Elliot AJ, Harris GS. The present status of the diagnosis and treatment of periphlebitis retinae (Eales' disease). Can J Ophthalmol 1969; 4: 117-122.

6 Weber M. [Eales] [Article in French]. J Fr Ophtalmol 2001; 24: 984-986.

7 Ishaq M, Niazi MK. Usefulness of pars plana vitrectomy in managing asymptomatic eyes of Eales' disease. J Ayub Med Coll Abbottabad 2003; 15: 50-53.

8 Ishaq M, Niazi MK. Usefulness of laser photocoagulation in managing asymptomatic eyes of Eales disease. J Ayub Med Coll Abbottabad 2002; 14: 22-25.

9 Pathengay A, Pilli S, Das T. Intravitreal triamcinolone acetonide in Eales' disease: a case report. Eye 2005; 19 711-713.

10 Agrawal S, Agrawal J, Agrawal TP. Intravitreal triamcinolone acetonide in Eales disease. Retina. 2006; 26(2): 227-229.

11 Smithen LM, Ober MD, Maranan L, Spaide RF. Intravitreal triamcinolone acetonide and intraocular pressure. $A m \mathrm{~J}$ Ophthalmol. 2004; 138(5): 740-743. 